\title{
Ccr7 null mice are protected against diet- induced obesity via Ucp1 upregulation and enhanced energy expenditure
}

\author{
Tomomi Sano', Taiki Sanada', Yusuke Sotomaru², Takanori Shinjo ${ }^{3}$, Misaki Iwashita', Akiko Yamashita',
} Takao Fukuda ${ }^{1}$, Terukazu Sanui ${ }^{1}$, Tomoichiro Asano ${ }^{4}$, Takashi Kanematsu ${ }^{5}$ and Fusanori Nishimura ${ }^{1 *}$

\begin{abstract}
Background: The chemokine receptor CCR7, expressed on various immune cells, is associated with cell migration and lympho-node homing. Mice lacking Ccr7 are protected from diet-induced obesity and subsequent insulin resistance. We evaluated the mechanism underlying these protective effects from the standpoint of energy expenditure.

Methods: Wild-type and Ccr7 null mice were fed a high-fat diet, and the regulation of energy metabolism and energy metabolism-related molecules, e.g., Ucp1, Cidea, and Pgc1a, were evaluated.

Results: Food intake did not differ between groups. $\mathrm{O}_{2}$ consumption and $\mathrm{CO}_{2}$ production were higher in $\mathrm{Ccr} 7$ null mice than in wild-type mice, despite a similar respiratory quotient and glucose and lipid utilization, suggesting that energy expenditure increased in Ccr7 null mice via enhanced metabolism. In white adipose tissues of Ccr7 null mice, Prdm 16, Cd137, Tmem26, Th, and Tbx1 expression increased. Similarly, in brown adipose tissues of Ccr7 null mice, Dio2, Pgcla, Cidea, Sirt1, and Adiponectin expression increased. In both white and brown adipose tissues, Ucp1 gene and protein expression levels were higher in null mice than in wild-type mice.
\end{abstract}

Conclusions: In Ccr7 null mice, browning of white adipocytes as well as the activation of brown adipocytes cause enhanced energy metabolism, resulting in protection against diet-induced obesity.

Keywords: Obesity, Energy expenditure, Brown adipose tissue, Adipose tissue, Inflammation

\section{Background}

It is well accepted that obesity increases the risk of other related complications such as insulin resistance and atherosclerosis. It is also suggested that obesity-induced inflammatory changes accompanied by the infiltration of immune cells into adipose tissue play crucial roles in the establishment of such complications. The number of obese subjects is still increasing in many parts of the world due possibly to the rapid economic changes, and, thus, the development of new and effective therapeutic strategy against obesity and/or insulin resistance is still urgently needed. We believe that adipose tissue browning is one such strategy against obesity.

\footnotetext{
*Correspondence: fusanori@dent.kyushu-u.ac.jp

${ }^{1}$ Section of Periodontology, Kyushu University Faculty of Dental Science,

3-1-1 Maidashi, Higashi-ku, Fukuoka 812-8582, Japan

Full list of author information is available at the end of the article
}

Adipose tissues are classified into white (WAT) and brown adipose tissue (BAT). The majority of adipose tissues in adults are believed to be WAT, with abundant triglycerides in adipocytes. BAT utilizes lipids as a substrate and produces heat. The volume of BAT is greater in neonatal infants than in adults, and individual differences in the rate of decline and activity are associated with the development of obesity [1]. Thus, the activation of BAT is a therapeutic target for obesity.

Heat production in BAT depends on the activity of uncoupling protein 1 (UCP1), a proton channel involved in uncoupling ATP synthesis, located in the inner membrane of mitochondria. It produces heat in response to various stimuli [2]. The loss of function of Ucp1 in mice accelerates the development of obesity in response to a high-fat diet [3], while the overexpression of Ucp1 in WAT results in protection against diet-induced obesity in mouse models [4]. In WAT, brown adipocytes, also

(c) The Author(s). 2019 Open Access This article is distributed under the terms of the Creative Commons Attribution 4.0 International License (http://creativecommons.org/licenses/by/4.0/), which permits unrestricted use, distribution, and 
called brite or beige adipocytes, are observed. In WATs of KK-Ay mice fed water containing acetate for 16 weeks, beige-related gene expression is upregulated [5]. Since beige adipocytes also produce heat, similar to brown adipocytes, and enhance energy expenditure, conversion from white adipocytes to beige adipocytes is a particularly interesting subject for the development of therapeutic strategies against obesity.

CCR7 is expressed on the surfaces of dendritic cells and certain T- and B-lymphocytes. It acts as a chemokine receptor for CCL19. CCR7 is also expressed on inflammatory M1 but not anti-inflammatory M2 macrophages. We previously reported that Ccl19 expression is markedly upregulated in adipocytes co-cultured with macrophages in the presence of toll like receptor- 4 ligand, a bacterial endotoxin. In fact, the Ccl19 concentrations in the sera of $\mathrm{ob} / \mathrm{ob}$ and high-fat diet-induced obese mice increase dramatically following endotoxin infusion via the tail vein. Furthermore, mice lacking Ccr7 are protected from dietinduced obesity. In these mice, we also observed the adipose tissue expression of adiponectin, liver expression of AdipoR1 and AdopoR2, as well as heat production in cold conditions [6]. These findings are supported by studies by other groups [7], but opposing results have also been obtained [8]. We hypothesized that Ccr7 may play important role in browning process as loss of function of Ccr7 results in the suppression of the development of obesity and/or insulin resistance. CCR7 is a chemokine receptor for many immune cells as mentioned. Therefore, in this study, to verify our previous results, we aimed to see the biological relationship between immune cell recruitment into the adipose tissue by Ccr7 and metabolic regulation system of energy expenditure.

\section{Methods}

\section{Generation of Ccr7 null mice}

Ccr7 null mice were a generous gift from Dr. Martin Lipp at the Department of Tumor Genetics and Immunogenetics, Max-Delbruck-Center of Molecular Medicine, Germany. The generation of Ccr7 null mice was explained in detail in a previous study; mice were kept under specific pathogen-free conditions until use [9].

\section{Animals}

Male Ccr7 null (KO) mice $(n=6)$ and wild-type (WT) C57BL/6 J mice $(n=6)$ were housed under specific pathogen-free conditions at the Kasumi Laboratory Animal Center of Hiroshima University under a 12-h light/dark cycle at $23 \pm 2{ }^{\circ} \mathrm{C}$. $\mathrm{KO}$ and WT mice were not from the same colony. Mice were fed a high-fat diet (HFD; 60.7\% fat, $17.9 \%$ protein, $21.4 \%$ nitrogen free extracts; Oriental Yeast, Tokyo) from 8 weeks of age, and male mice were used in all experiments. This study was approved by the Animal Care and Use Committee of Hiroshima University (permission number: A15-81) and was performed in accordance with the Guide for Hiroshima University Animal Experimentation Regulation. Body weights were monitored and food intake was recorded by subtracting the amount of food left in the cage from the daily amount given, at 2 p.m. (day) and 2 a.m. (night). At 20 weeks of age, the mice were sacrificed.

\section{Locomotor activity analysis}

A locomotor activity analysis was performed according to previously reported methods [10]. Locomotor activity was recorded using a video camera (HDR-XR550V; Sony, Tokyo, Japan) and results were analyzed using the ANY-maze video tracking system (Stoelting Co., Wood Dale, IL, USA). Mice fed an HFD were maintained in a cage (a square arena, $30 \mathrm{~cm} \times 30 \mathrm{~cm}$, with 40 -cm high opaque walls) for 1 week before 18 weeks of age, and the total distance traveled was measured for $24 \mathrm{~h}$.

\section{Analysis of energy metabolism}

Nineteen-week-old WT and KO mice fed the HFD were subjected to metabolic analyses. Oxygen consumption $\left(\mathrm{VO}_{2}\right)$ and carbon dioxide production $\left(\mathrm{VCO}_{2}\right)$ were measured using a computer-controlled open-circuit calorimetry system (Oxymax System; Columbus Instruments, Columbus, OH, USA). All mice were acclimatized for $24 \mathrm{~h}$ before measurements, and $\mathrm{VO}_{2}$ and $\mathrm{VCO}_{2}$ data were recorded for 2 days. The respiratory exchange ratio was calculated as the ratio of $\mathrm{VCO}_{2}$ to $\mathrm{VO}_{2}$. Energy expenditure was calculated using the following equation: heat $=$ $\mathrm{CV} \times \mathrm{VO}_{2}$, where $\mathrm{CV}=3.815+1.232 \times$ respiratory exchange ratio $(\mathrm{CV}$, calorific value based on the observed respiratory exchange ratio).

\section{Histochemistry}

Epididymal and inguinal WATs (eWAT and iWAT, respectively), BAT, and the muscle were fixed with $4 \%$ paraformaldehyde phosphate buffer solution and embedded in paraffin. Muscle and iWAT samples were subjected to standard hematoxylin-eosin staining [10]. Cell areas were measured using ImageJ. Immunohistochemical staining of adipose tissue was performed using paraffin sections with F4/80 (mouse macrophage and microglial marker), Cd11b (mouse macrophage and microglial marker), and Ucp1 antibodies.

\section{Quantitative real-time PCR}

Quantitative Real-time PCR was performed according to the same methods reported previously [11]. cDNA was constructed using the ReverTra Ace qPCR RT Kit (Toyobo, Tokyo, Japan). The real-time PCR was performed using the KAPA SYBR FAST qPCR Kit (ABI Prism, Applied Biosystems, Foster city, CA), and the reactions were conducted on the 7300 Real-Time PCR system 
(Applied Biosystems, Foster city, CA). The mRNA expression levels of Ucp1, Cidea, Pgcla, Prdm16, Cd137, Tmem26, Th, and $T b x 1$ in epididymal adipose tissues were quantified, and the levels of Ucp1, Dio2, Pgc1a, Cidea, Sirt1, and Adiponectin in brown adipose tissues were quantified. The primer sequences are listed in Table 1. Data were normalized against Gapdh levels unless specified and were calculated as fold change values relative to expression in control WT mice. In some experiments, the data were also normalized against $\beta$-actin levels for better confirmation.

\section{Immunoblot assay}

BAT and eWAT were homogenized in a lysis buffer containing $50 \mathrm{~mm}$ Tris- $\mathrm{HCl}, \mathrm{pH} 7.4,150 \mathrm{~mm} \mathrm{NaCl}, 1 \mathrm{~mm}$ NaF, $1 \mathrm{~mm}$ EDTA, $1 \mathrm{~mm}$ EGTA, 1\% Triton X-100, $500 \mu \mathrm{M}$ $\mathrm{Na}_{3} \mathrm{VO}_{4}$, and protease inhibitors. After $30 \mathrm{~min}$ of incubation on ice, cell lysates were centrifuged at $20,000 \times g$ for $30 \mathrm{~min}$, and supernatants were collected. The protein concentration was measured using the Protein Assay Rapid Kit (Wako, Osaka, Japan), and the lysate samples were used for immunoblotting. The primary antibodies were as follows: anti-Gapdh antibody (Proteintech, Rosemount, IL, USA) and anti-Ucp1 antibody (Abcam, Cambridge, UK). For the secondary antibodies, Anti-rabbit IgG, HRP-linked Antibody (Cell Signaling, Danvers, MA, USA) was used. An Enhanced Chemiluminescence Western Detection Reagent (Nacalai Tesque) was used for signal development. Resultant signals were captured using an ImageQuant LAS 4000 Mini Detection System (GE Healthcare Life Sciences) . The density of each band was analyzed using ImageJ.

\section{Statistical analysis}

Data are expressed as means \pm S.E. Statistical analyses were performed using Student's $t$-tests within the Excel software package (Microsoft). Values of $P<0.05$ were considered significant.

\section{Results}

Food intake in both the light and dark cycles did not differ significantly between WT and KO mice (Fig. 1a). We first confirmed the changes of body weight gain in each group as reported in our previous study [6] and performed subsequent experiments. We next evaluated the ratio of each tissue weight against the total body weight (Fig. 1b). Although the weights of liver and two types of muscle did not differ between the two mouse groups, adipose tissue weights were significantly lower ( $P$ values; Epididymal WAT 0.0004, Inguinal WAT 0.0014 , and BAT 0.0216) in KO mice than in WT mice. KO mice fed a high-fat diet had $30 \%$ of the epididymal WAT in WT mice, $16.4 \%$ of the inguinal WAT, and $65 \%$ of the BAT. We also previously did not observe fatty liver in $\mathrm{KO}$ mice fed a high-fat diet. In this study, we further explored the histological features of muscle tissues. However, no apparent differences were detected in muscle tissues with respect to ectopic lipid deposition (Additional file 1: Figure S1a). In the WAT of KO mice, no apparent F4/80, Cd11b-positive cells were observed, while in WT mice, the accumulation of these positive cells was observed (Fig. 1c). In the subcutaneous fat, adipocyte size did not differ between WT and KO mice (Additional file 1: Figure S1b).

Additionally, in $\mathrm{KO}$ fed a high-fat diet, adipocyte maturation was less than that in WT mice fed a high-fat diet. Therefore, we assessed energy expenditure in both mice. We monitored spontaneous motor activity in both the light and dark using a 12-h cycle. However, no significant differences were observed (Fig. 2a). $\mathrm{O}_{2}$ consumption and $\mathrm{CO}_{2}$ production were significantly higher $\left(P\right.$ values; $\mathrm{O}_{2}$

Table 1 Primers used in the study

\begin{tabular}{lll}
\hline Gene & Forward primer & Reverse primer \\
\hline Gapdh & AATGTGTCCGTCGTGGATCTGA & GATGCCTGCTTCACCACCTTCT \\
Ucp1 & CACCTTCCCGCTGGACACT & CCCTAGGACACCTTTATACCTAATGG \\
Cidea & ATCACAACTGGCCTGGTACG & TACTACCCGGTGTCCATTCT \\
Pgcia & AGCCGTGACCACTGACAACGAG & GCTGCATGGTTCTGAGTGCTAA \\
Prdm16 & CAGCACGGTGAAGCCATTC & GCGTGCATCCGCTTGTG \\
Cd137 & GGCCGTTAGGAAAGGGACA & CAGGAGTCATGCAGAGGCAA \\
Tmem26 & GAAACCAGTATTGCAGCACCC & CCCATTCCATTGGTGGCTCT \\
Th & CCTGGAGTACTTTGGCGCT & GGGAACCAGGGAACCTTGTC \\
Tbx1 & CCGGTGAAGAAGAACCCGAA & AACATTCGTCTGCCTGCCTT \\
Dio2 & TGAACCAAAGTTGACCACCAG \\
Sirt1 & CAGTGGGTGCACGTCTCCAATC & TGTGAAGTACTGCAGGAGTGTAAA \\
Adiponectin & GCATAGATACCGTCTCTTGATCTGAA & CCAACCTGCACAAGTCCCTT \\
\hline
\end{tabular}



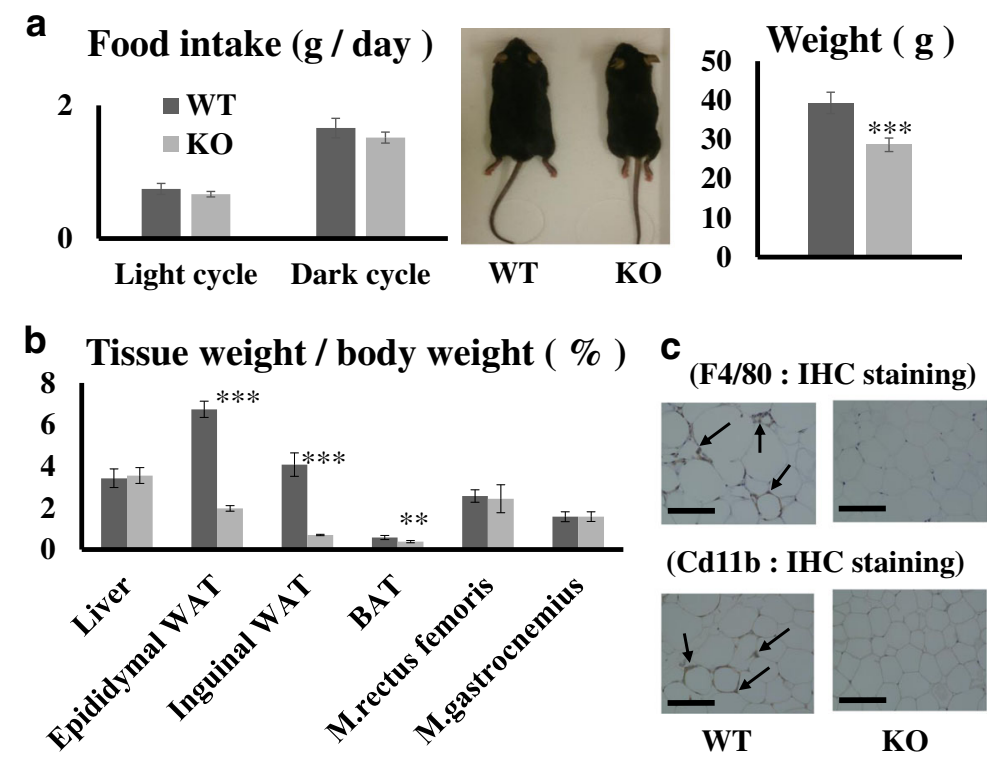

Fig. 1 Differences in food intake and weight between C-C chemokine receptor type 7 (Ccr7) null mice and wild-type mice. a Food intake during light and dark cycles and body weight at 20 weeks. b Ratios of the weights of each tissue and organ against the total weight. c Immunostaining of F4/80 and Cd11b in eWAT of each mouse

light cycle 1.09E-14, dark cycle 4.99E-34, $\mathrm{CO}_{2}$ light cycle 1.65E-11, dark cycle 4.29E-26) in KO mice fed a high-fat diet than in WT mice fed a high-fat diet (Fig. 2b). The respiratory quotient did not differ between WT and KO mice (Fig. 2c). When we calculated energy expenditure, dark cycle energy expenditure in $\mathrm{KO}$ mice was significantly greater (P value; 0.0016$)$ than that in WT mice fed a high-fat diet (Fig. 2d).

To understand the molecular basis underlying the protection of $\mathrm{KO}$ mice from diet-induced obesity, we compared the expression of genes related to energy expenditure in BATs of these mice. In $\mathrm{KO}$ mice, the expression of genes encoding Ucp1 and other BAT markers, such as Dio2, Pgc1 $\alpha$, Cidea, Sirt1, and Adiponectin were significantly upregulated ( $P$ values; Ucp1 3.04E-05, Dio2 7.30E-05, Pgc1 $\alpha$ 0.0005, Cidea 0.0018, Sirt1 0.0015, and Adiponectin 8.94E06) compared with levels in WT mice fed a high-fat diet (Fig. 3a, Additional file 2: Figure S2a). A western blotting analysis revealed that Ucp1 protein expression was also up-regulated in the BAT of $\mathrm{KO}$ mice fed a highfat diet (Fig. 3b). Similarly, strong immunostaining of Ucp1 was observed in the BAT of KO mice (Fig. 3c).

We next assessed the expression of genes associated with energy expenditure in WAT. In KO mice fed a high-fat diet, the expression levels of Ucp1, Cidea, and $P g c 1 \alpha$ were higher than those in WT mice (Fig. 4a, Additional file 2: Figure S2b), while in subcutaneous adipose tissue, no apparent differences in $U_{c p} 1$ were observed (Additional file 2: Figure S2c). Furthermore, in the WAT of KO mice, the expression levels of factors that promote browning, such as Prdm18, Cd137, Teme26, Th, and Tbxl, were significantly higher (P values; $\operatorname{Prdm} 18$ 0.0012, Cd137 0.0003, Tmem26 0.0019, Th 0.0290, and Tbx1 0.0006) than those in WT mice (Fig. 4b). Ucp1 protein expression was also greater in $\mathrm{KO}$ mice than in WT mice (Fig. 4c); strong Ucp1 immunostaining was observed in the WAT of these mice (Fig. 4d). Ucp1 protein expression in subcutaneous adipose tissues did not differ between WT and KO mice (Additional file 2: Figure S2d). Taken together, in $\mathrm{KO}$ mice, adipose tissue browning is induced by a high-fat diet.

\section{Discussion}

In this study, we started feeding HFD for WT and Ccr7 null mice at 8 weeks of age till 20 weeks. Since these mice generally reach sexual maturity at 8 weeks, we consider the mice at 8 weeks adult. And when we feed WT mice HFD, the body weight usually reaches plateau at 20 weeks. We therefore performed the experiments between 8 weeks and 20 weeks of age. We previously reported that Ccr7 null mice are protected from dietinduced obesity [6]. While WAT stores excess energy, BAT utilizes stored energy and produces heat. However, WAT acquires a BAT-like phenotype by browning and expresses BAT-specific genes, such as heat-producing genes. Ccr7 null mice fed a high-fat diet showed increased energy expenditure, the browning of WAT, as well as the activation of BAT. These factors may explain why these mice were protected from diet-induced obesity. Adipose tissue volume of both types of WAT (eWAT and iWAT) itself was smaller in Ccr7 null mice than in WT mice. However, adipocyte size was only different in 

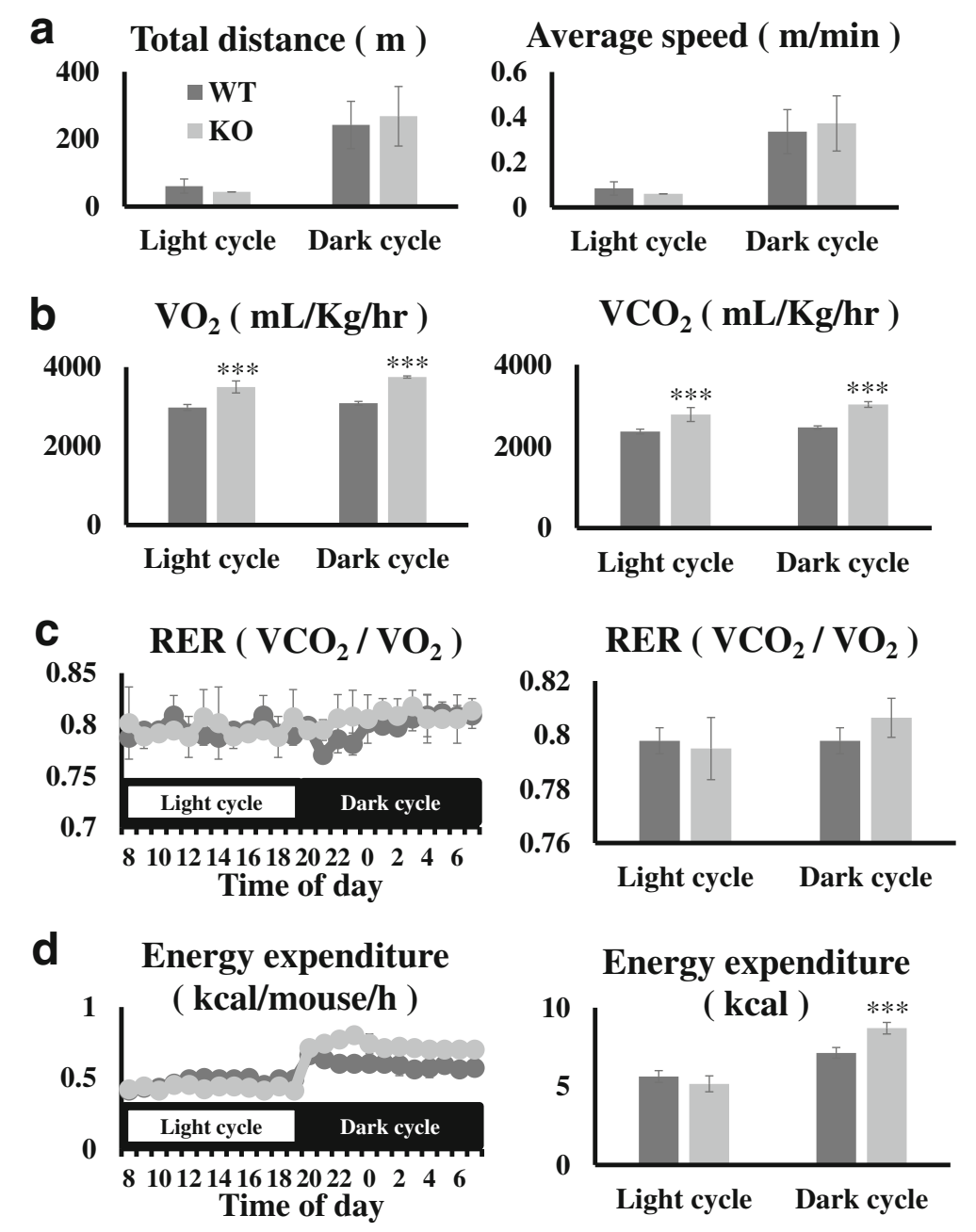

Fig. 2 Locomotor activity and oxygen consumption in each mouse group. a Locomotor activity of 18-week-old wild-type (WT; HFD, $n=6)$ and $\mathrm{Ccr} 7$ null (KO; HFD, $n=6$ ) mice. Total traveled distance (day, 8 a.m. to 8 p.m.; night, 8 p.m. to 8 a.m.) was analyzed using the ANY-maze video tracking system. $\mathbf{b}$ In 19-week-old WT ( $\mathrm{HFD}, \mathrm{n}=6)$ and $\mathrm{KO}(\mathrm{HFD}, \mathrm{n}=6)$ mice, oxygen consumption $\left(\mathrm{VO}_{2}\right)$ and carbon dioxide production $\left(\mathrm{VCO}_{2}\right)$ were assessed by an indirect calorimetric system over a 24-h period with a 12-h light/dark cycle (day from 8 a.m. to 8 p.m.); the respiratory exchange ratio (RER) $\mathbf{c}$ and energy expenditure $\mathbf{d}$ are shown. Data are presented as means \pm S.E. ${ }^{* * *}, p<0.001$ versus the corresponding WT value

eWAT. Although speculative, adipocyte browning could have suppressed hypertrophic changes in eWAT. The similar phenomenon is reported in other studies $[12,13]$.

Uncoupling protein 1 is localized in the inner membrane of mitochondria and uncouples ATP synthesis. UCP1 plays important roles in the maintenance of energy homeostasis and protection against obesity. Ucp1 null mice develop obesity, while the overexpression of Ucp1 in mice results in protection from diet-induced obesity [4, 14]. UCP1 homologues, i.e., UCP2 and UCP3, have similar roles and are potential therapeutic target molecules against obesity. UCP2 is ubiquitously expressed at low levels throughout the body, while UCP3 expression is limited to the skeletal muscle and cardiac muscles $[15,16]$. Mice with muscle-specific overexpression of Ucp3 did not develop obesity and showed increased energy metabolism and normal glucose tolerance upon high-fat feeding [17].

In this study, we did not observe significant differences in the expression of $U c p 2$ and $U c p 3$ between mice (data not shown). Thus, we hypothesized that Ucp1 was the primary molecule responsible for regulating energy expenditure in Ccr7 null mice. In WT mice fed a highfat diet, excess energy accumulates in adipose tissues and accelerates adipose tissue inflammation.

We observed Cd11b- and F4/80-positive macrophage infiltration in WT mice fed a high-fat diet but not in Ccr7 null mice fed a high-fat diet; it is possible that this can be explained by the protection against obesity and reduced inflammation in the adipose tissue via increased energy expenditure in these mice. We observed high Sirt1 expression in Ccr7 null mice, which activates Ppary 

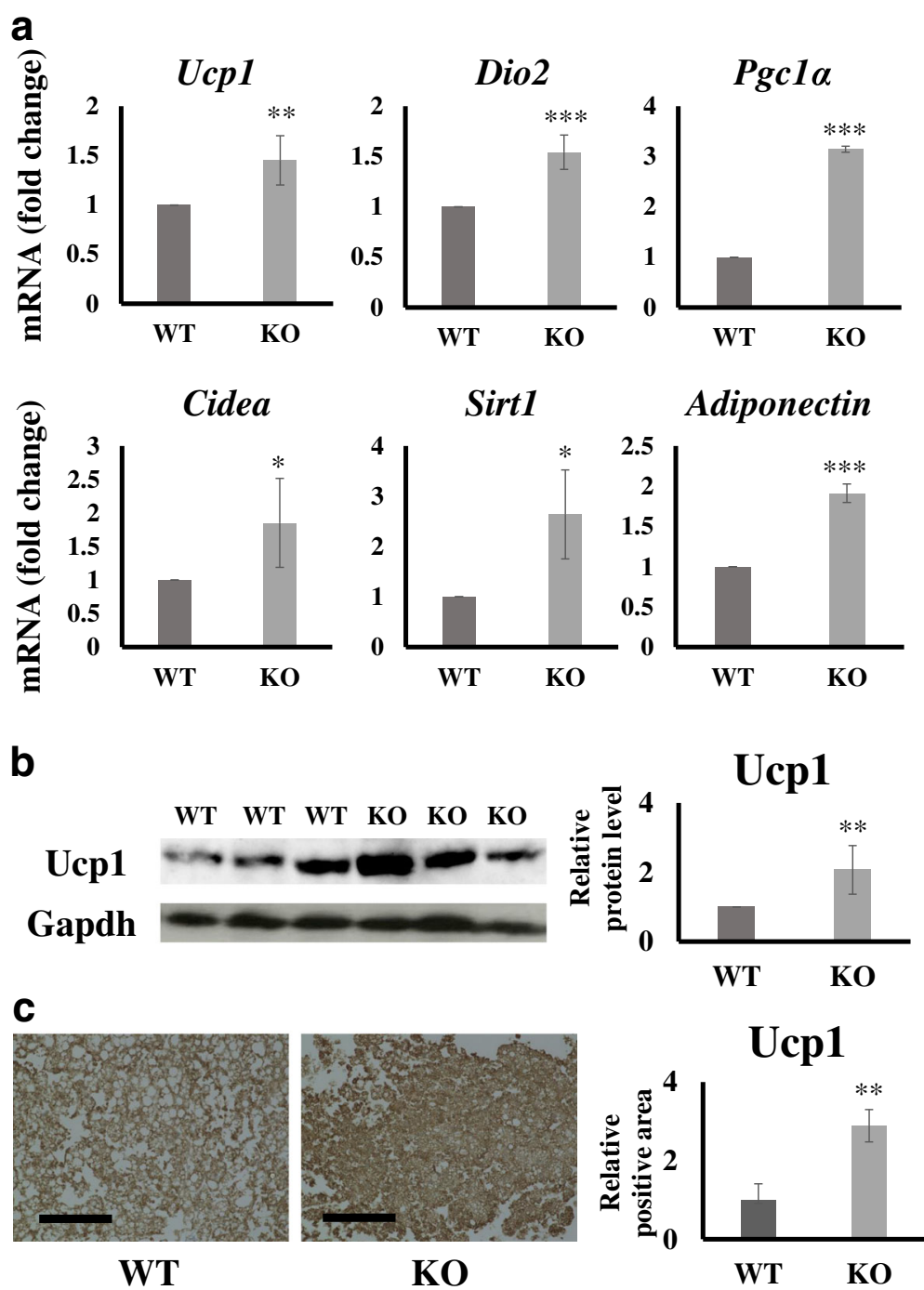

WT

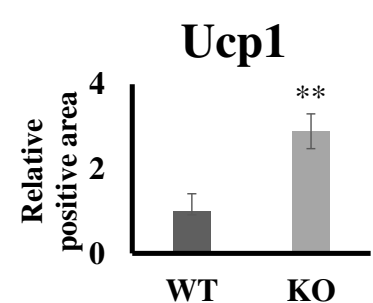

Fig. 3 Analysis of brown adipose tissue (BAT)-related gene and protein expression levels. a BAT-related gene expression levels in each test group. Test mice include those fed a high-fat diet as described in the "Materials and methods" section. Gene expression was analyzed by real-time PCR. Data are normalized against Gapdh and expressed as fold changes relative to the expression level in WT mice. $\mathbf{b}$ Detection of Ucp 1 by a western blot analysis in BAT. Western blot analyses were performed as described in the "Materials and methods" section. c Ucp1 staining in BAT, bar: $100 \mu \mu m$. Brown parts are positively stained for Ucp1. ${ }^{*} p<0.05,{ }^{* *} p<0.01{ }^{* * *} p<0.001$ by Student's $t$-test

by de-acetylation and accelerates the browning of WAT [18]. Incubation of pre-adipocytes derived from murine adipose tissues with a Ppary agonist results in increased expression of Ucp1 at the gene and protein levels [19]. High Ppary expression was also noted in our previous study [6]. Ppary null mice are characterized by increased CD11b + CD11c + F4/80+ macrophages [20]. High Ppary expression in Ccr7 null mice is accompanied by the browning of WAT and decreased infiltration of macrophages. High-fat diets are associated with an increased ratio of $\mathrm{F} 4 / 80+\mathrm{CD} 11 \mathrm{c}+\mathrm{CCR} 7+$ macrophages [7]. Therefore, CCR7 may play an important role in regulating adipose tissue inflammation.
Cold stimulation, diet, and exercise may regulate Ucp1 expression [3, 21]. However, these factors did not influence the results of our experiments, which were performed under a normal, consistent temperature. Both mice consumed similar amounts of foods and showed similar motor activity. Ucp1 expression is induced by oxidative stress [22]. We noted increased Pgc1 $\alpha$ expression in the adipose tissues of $\mathrm{Ccr} 7$ null mice fed a high-fat diet. PGC1 $\alpha$ is known to elevate oxidative stress in adipocytes [23]. Oxidative stress increases Pgc1 $\alpha$ expression and Pgc1 $\alpha$ interacts with nuclear receptors, such as retinoid receptor Rxr and Ppar, and up-regulates mitochondrial synthesis and Ucp1 expression in white adipocytes 

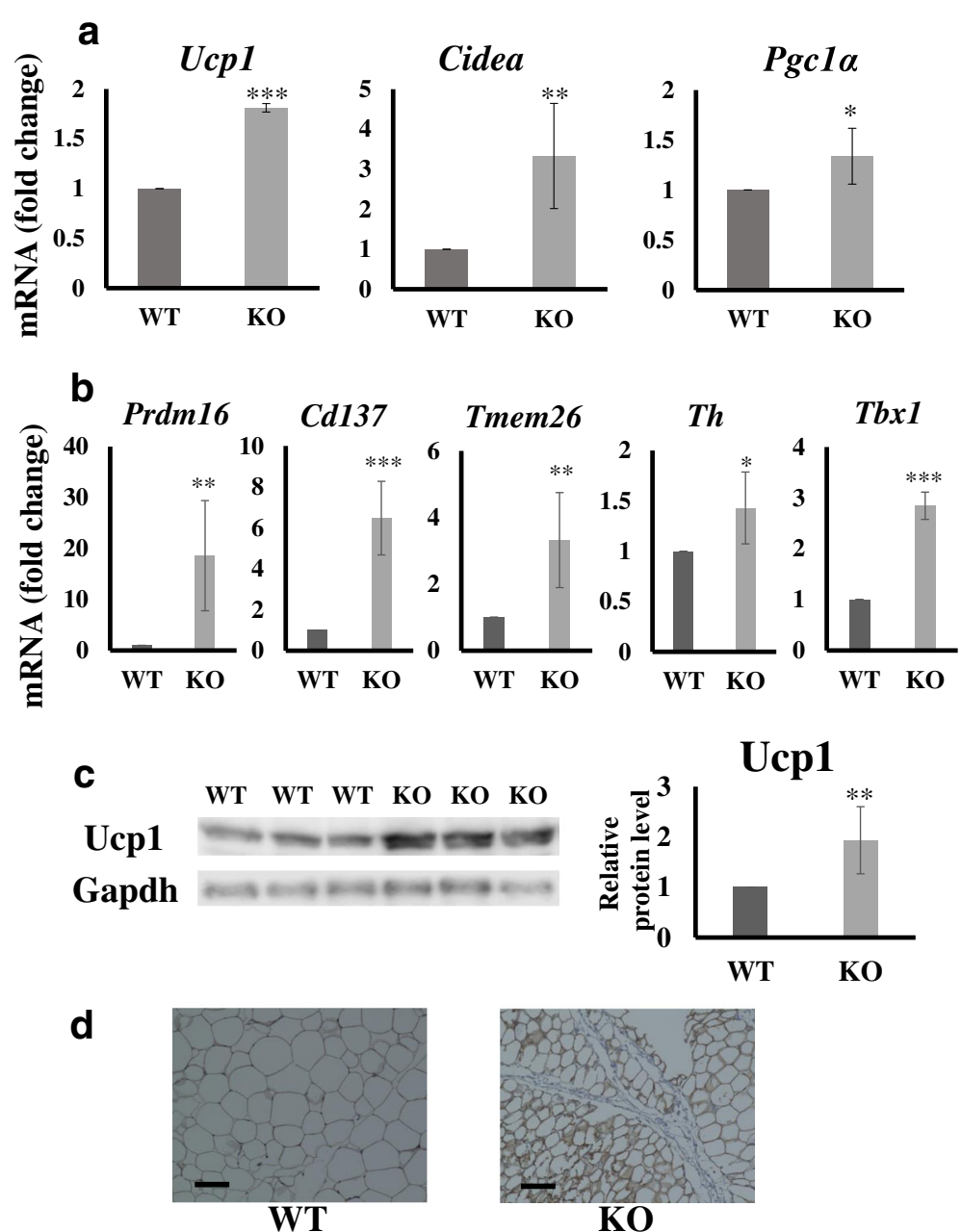

Fig. 4 Analysis of white adipose tissue (WAT)-related gene and protein expression levels. $\mathbf{a}, \mathbf{b}$ eWAT gene expression levels in each test group. Test mice include those fed a high-fat diet as described in the "Materials and methods" section. Gene expression was analyzed by real-time PCR. Data are normalized against Gapdh and expressed as fold changes relative to the expression level in WT mice. c Detection of Ucp1 by a western blot analysis in eWAT. Western blot analyses were performed as described in the "Materials and methods" section. Brown parts are positively stained for Ucp1. d Ucp1 staining, bar: $100 \mu \mathrm{m}$. ${ }^{*} p<0.05,{ }^{* *} p<0.01{ }^{* * *} p<0.001$ by Student's $t$-test

$[24,25]$. Thus, it is possible that the browning of WAT in Ccr7 null mice fed a high-fat diet is mediated by oxidative stress and subsequent Pgc1 $\alpha$ expression. In fact, we previously performed gene expression profiling of adipocytes co-cultured with macrophages in the presence of bacterial endotoxins, and superoxide dismutase 2 (also known as mitochondrial super oxide dismutase) gene expression was markedly up-regulated in adipocytes upon endotoxin stimulation [26]. Superoxide dismutase 2 is a mitochondria-specific superoxide scavenger [27]. Thus, in the mitochondria of WT mouse adipose tissue with macrophage infiltration, the superoxide scavenging system may function as secondary factors, while the scavenging system does not function consistently in adipose tissue without macrophage infiltration. Pgc1 $\alpha$ is a regulator of mitochondrial biogenesis. In the obese state, it is known that TNF- $\alpha$, which is highly expressed in immune cells, inhibits Ucp1 expression in adipocytes [28]. Thus, in the current study, it is possible that increased TNF- $\alpha$ expression accompanied by immune cell infiltration suppressed Ucp1 expression in adipose tissue in co-operation with reduced mitochondrial biogenesis accompanied by lower Pgc1 $\alpha$ expression as mentioned above in WT mice fed a high-fat diet. In fact, inflammatory macrophage infiltration is reported to suppress adipocyte browning [29]. Taken together, in obese adipose tissues where increased amounts of dendritic cells and macrophages are infiltrated, browning may be suppressed, and such obese state may further accelerate the inhibition of energy expenditure.

In human adults, brown adipose tissue was not clearly identified before. However, FDG-PET (positron emission tomography with fluorodeoxy-glucose) analyses clearly 
demonstrated the existence of brown adipose tissues in human adults, and heat production was confirmed in such brown adipose tissues [30]. Furthermore, exercise or cold temperature stimulation toward human healthy adults result in the increase in serum IRISIN and FGF21, and in vitro study showed that IRISIN and FGF21 up-regulated UCP1 expression and subsequent heat production [31]. Furthermore, in the human white adipose tissue, cold temperature promotes adipocytes to ectopically express UCP1 and, thus, it is suggested that browning may greatly regulate metabolism [32]. Moreover, human visceral fat is without doubt a great contributor for obesity and related complications, but can be a target for therapy by converting adipocytes into browning [33].

\section{Conclusions}

Ccr7 null mice are protected from diet-induced obesity. The browning of WAT and activation of BAT are the primary mechanisms underlying this protection. Therefore, CCR7 is a potentially effective therapeutic target against obesity and/or related diseases.

\section{Additional files}

Additional file 1: Figure S1. Summary of hematoxylin-eosin (HE) staining results. (a) HE staining (muscle). bar, $100 \mu \mathrm{m}$. (b) HE staining (iWAT). bar, $100 \mu \mathrm{m}$. (c) Inguinal adipocyte size in the test mice. (PPTX $561 \mathrm{~kb}$ )

Additional file 2: Figure S2. (a) Ucpl gene expression levels in BAT. (Data were normalized against $\beta$-actin levels.) (b) Ucp 1 gene expression levels in eWAT. (Data were normalized against $\beta$-actin levels.) (c) Ucpl gene expression levels in iWAT (Data were normalized against Gapdh levels). (d) Ucp1 staining in iWAT, bar: $100 \mu \mathrm{m}$. Brown parts are positively stained for Ucp1. (PPTX $591 \mathrm{~kb}$ )

\section{Abbreviations \\ Cidea: Cell death activator; Dio2: iodothyronine deiodinase 2; Pgc1a: Peroxisome proliferator activated receptor gamma coactivator 1 alpha; Prdm16: PR domain containing 16; Sirt1: sirtuin 1; Tbx1: T-box 1; Th: tyrosine hydroxylase; Tmem26: Transmembrane protein 26}

\section{Acknowledgments}

This work was supported by a Grant-in-Aid from the Japan Society for the Promotion of Science [grant numbers 16H05555, 18 K17071].

\section{Authors' contributions}

T. Sano, T. Sanada, Y. S., T. Shinjo, M. I., A. Y., T. F. and T. Sanui. performed the experiments. F. N., T. A., and T. K. conceived the study. F. N. supervised the study. F. N. and T. Sano wrote the paper. All authors interpreted the data. All authors read and approved the final manuscript.

\section{Funding}

No potential conflicts of interest relevant to this article were reported. This work was supported by a Grant-in-Aid from the Japan Society for the Promotion of Science [grant numbers 16H05555, 18 K17071].

\section{Availability of data and materials}

The datasets used and/or analysed during the current study are available from the corresponding author on reasonable request.

\section{Ethics approval and consent to participate}

This study was approved by the Animal Care and Use Committee of Hiroshima University (permission number: A15-81) and was performed in accordance with the Guide for Hiroshima University Animal Experimentation Regulation.

\section{Consent for publication}

Not applicable.

\section{Competing interests}

The authors declare that they have no competing interests.

\section{Author details}

${ }^{1}$ Section of Periodontology, Kyushu University Faculty of Dental Science, 3-1-1 Maidashi, Higashi-ku, Fukuoka 812-8582, Japan. ${ }^{2}$ Natural Science Center for Basic Research and Development, Hiroshima University, Hiroshima, Japan. ${ }^{3}$ Section of Vascular Cell Biology, Joslin Diabetes Center, Harvard Medical

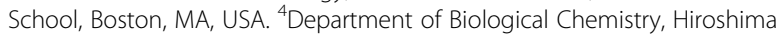
University Institute of Biomedical and Health Sciences, Hiroshima, Japan. ${ }^{5}$ Department of Cellular and Molecular Pharmacology, Hiroshima University Institute of Biomedical and Health Sciences, Hiroshima, Japan.

Received: 20 December 2018 Accepted: 26 June 2019

Published online: 04 July 2019

\section{References}

1. Gesta S, Tseng YH, Kahn CR. Developmental origin of fat: tracking obesity to its source. Cell. 2007;131:242-56.

2. Nedergaard J, Ricquier D, Kozak LP. Uncoupling proteins: current status and therapeutic prospects. EMBO Rep. 2005:6:917-21.

3. Feldmann HM, Golozoubova V, Cannon B, Nedergaard J. UCP1 ablation induces obesity and abolishes diet-induced thermogenesis in mice exempt from thermal stress by living at thermoneutrality. Cell Metab. 2009;9:203-9.

4. Kopecky J, Clarke G, Enerbäck S, Spiegelman B, Kozak LP. Expression of the mitochondrial uncoupling protein gene from the aP2 gene promoter prevents genetic obesity. J Clin Invest. 1995;96:561-5.

5. Hanatani S, Motoshima H, Takaki Y, Kawasaki S, Igata M, Matsumura T, Kondo T, Senokuchi T, Ishii N, Kawashima J, et al. Acetate alters expression of genes involved in beige adipogenesis in 3T3-L1 cells and obese KK-ay mice. J Clin Biochem Nutr. 2016;59:207-14.

6. Sano T, Iwashita M, Nagayasu S, Yamashita A, Shinjo T, Hashikata A, Asano T, Kushiyama A, Ishimaru N, Takahama Y, et al. Protection from diet-induced obesity and insulin resistance in mice lacking CCL19-CCR7 signaling. Obesity. 2015;23:1460-71.

7. Hellmann J, Sansbury BE, Holden CR, Tang Y, Wong B, Wysoczynski M, Rodriguez J, Bhatnagar A, Hill BG, Spite M. CCR7 maintains nonresolving lymph node and adipose inflammation in obesity. Diabetes. 2016;65:2268-81.

8. Cho KW, Zamarron BF, Muir LA, Singer K, Porsche CE, DelProposto JB, Geletka L, Meyer KA, O'Rourke RW, Lumeng CN. Adipose tissue dendritic cells are independent contributors to obesity-induced inflammation and insulin resistance. J Immunol. 2016;197:3650-61.

9. Förster R, Schubel A, Breitfeld D, Kremmer E, Renner-Müller I, Wolf E, Lipp M. CCR7 coordinates the primary immune response by establishing functional microenvironments in secondary lymphoid organs. Cell. 1999;99:23-33.

10. Oue K, Zhang J, Harada-Hada K, Asano S, Yamawaki Y, Hayashiuchi M, Furusho H, Takata T, Irifune M, Hirata M, et al. Phospholipase C-related catalytically inactive protein is a new modulator of thermogenesis promoted by $\beta$-adrenergic receptors in brown adipocytes. J Biol Chem. 2016;291:4185-96.

11. Sano T, Nagayasu S, Suzuki S, Iwashita M, Yamashita A, Shinjo T, Sanui T, Kushiyama A, Kanematsu T, Asano T, et al. Epicatechin downregulates adipose tissue CCL19 expression and thereby ameliorates diet-induced obesity and insulin resistance. Nutr Metab Cardiovasc Dis. 2017;27:249-59.

12. Yu J, Lv Y, Wang F, Kong X, Di W, Liu J, Sheng Y, Lv S, Ding G. MiR27b-3p inhibition enhances Browning of Epididymal fat in high-fat diet induced obese mice. Front Endocrinol (Lausanne). 2019. https://doi.org/ 10.3389/fendo.2019.00038.

13. Han $Y$, Wu JZ, Shen JZ, Chen L, He T, Jin MW, Liu H. Pentamethylquercetin induces adipose browning and exerts beneficial effects in 3T3-L1 adipocytes and high-fat diet-fed mice. Sci Rep. 2017. https://doi.org/10.1038/s41598-017-01206-4. 
14. Li B, Nolte LA, Ju JS, Han DH, Coleman T, Holloszy JO, Semenkovich CF. Skeletal muscle respiratory uncoupling prevents diet-induced obesity and insulin resistance in mice. Nat Med. 2000;6:1115-20.

15. Boss O, Samec S, Dulloo A, Seydoux J, Muzzin P, Giacobino JP. Tissuedependent upregulation of rat uncoupling protein-2 expression in response to fasting or cold. FEBS Lett. 1997;412:111-4.

16. Fleury C, Neverova M, Collins S, Raimbault S, Champigny O, LeviMeyrueis C, Bouillaud F, Seldin MF, Surwit RS, Ricquier D, et al. Uncoupling protein-2: a novel gene linked to obesity and hyperinsulinemia. Nat Genet. 1997;15:269-72.

17. Clapham JC, Arch JR, Chapman H, Haynes A, Lister C, Moore GB, Piercy V, Carter SA, Lehner I, Smith SA, et al. Mice overexpressing human uncoupling protein-3 in skeletal muscle are hyperphagic and lean. Nature. 2000;406:415-8

18. Qiang L, Wang L, Kon N, Zhao W, Lee S, Zhang Y, Rosenbaum M, Zhao Y, Gu W, Farmer SR, et al. Brown remodeling of white adipose tissue by SirT1dependent deacetylation of Ppary. Cell. 2012;150:620-32.

19. Petrovic N, Walden TB, Shabalina IG, Timmons JA, Cannon B, Nedergaard J. Chronic peroxisome proliferator-activated receptor gamma (PPARgamma) activation of epididymally derived white adipocyte cultures reveals a population of thermogenically competent, UCP1-containing adipocytes molecularly distinct from classic brown adipocytes. J Biol Chem. 2010;285:7153-64.

20. Cipolletta D, Feuerer M, Li A, Kamei N, Lee J, Shoelson SE, Benoist C, Mathis D. PPAR- $\gamma$ is a major driver of the accumulation and phenotype of adipose tissue Treg cells. Nature. 2012;486:549-53.

21. Ringholm S, Grunnet Knudsen J, Leick L, Lundgaard A, Munk Nielsen M, Pilegaard H. PGC-1a is required for exercise- and exercise traininginduced UCP1 up-regulation in mouse white adipose tissue. PLOS One. 2013:8:e64123.

22. Echtay KS, Winkler E, Klingenberg M. Coenzyme Q is an obligatory cofactor for uncoupling protein function. Nature. 2000;408:609-13.

23. Matsuzawa-Nagata N, Takamura T, Ando H, Nakamura S, Kurita S, Misu H, Ota T, Yokoyama M, Honda M, Miyamoto K, et al. Increased oxidative stress precedes the onset of high-fat diet-induced insulin resistance and obesity. Metabolism. 2008;57:1071-7.

24. St-Pierre J, Drori S, Uldry M, Silvaggi JM, Rhee J, Jäger S, Handschin C,

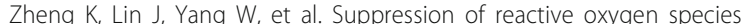
and neurodegeneration by the PGC-1 transcriptional coactivators. Cell. 2006:127:397-408.

25. Wu Z, Puigserver P, Andersson U, Zhang C, Adelmant G, Mootha V, Troy A, Cinti S, Lowell B, Scarpulla RC, et al. Mechanisms controlling mitochondrial biogenesis and respiration through the thermogenic coactivator PGC-1. Cell. 1999:98:115-24

26. Yamashita A, Soga $Y$, Iwamoto $Y$, Asano T, Li Y, Abiko Y, Nishimura F. DNA microarray analyses of genes expressed differentially in 3T3-L1 adipocytes co-cultured with murine macrophage cell line RAW264.7 in the presence of the toll-like receptor 4 ligand bacterial endotoxin. Int J Obes. 2008;32:1725-9.

27. Zelko IN, Mariani TJ, Folz RJ. Superoxide dismutase multigene family: a comparison of the CuZn-SOD (SOD1), Mn-SOD (SOD2), and EC-SOD (SOD3) gene structures, evolution, and expression. Free Radic Biol Med. 2002;33:337-49.

28. Sakamoto T, Takahashi N, Sawaragi Y, Naknukool S, Yu R, Goto T, Kawada T. Inflammation induced by RAW macrophages suppresses UCP1 mRNA induction via ERK activation in 10T1/2 adipocytes. Am J Physiol Cell Physiol. 2013:304:C729-38.

29. Parinandi NL, Magalang UJ. Avatars of adipose tissue: the saga of transformation of white fat, the villain into brown fat, the protector. Focus on "inflammation induced by RAW macrophages suppresses the UCP1 mRNA induction via ERK activation in 10T1/2 adipocytes". Am J Physiol Cell Physiol. 2013;304:C715-6.

30. Saito M, Okamatsu-Ogura Y, Matsushita M, Watanabe K, Yoneshiro T, Nio-Kobayashi J, Iwanaga T, Miyagawa M, Kameya T, Nakada K, et al. High incidence of metabolically active brown adipose tissue in healthy adult humans: effects of cold exposure and adiposity. Diabetes. 2009;58:1526-31.

31. Lee $P$, Linderman JD, Smith S, Brychta RJ, Wang J, Idelson C, Perron RM, Werner CD, Phan GQ, Kammula US, et al. Irisin and FGF21 are coldinduced endocrine activators of brown fat function in humans. Cell Metab. 2014;19:302-9.
32. Ohno H, Shinoda K, Spiegelman BM, Kajimura S. PPARy agonists induce a white-to-brown fat conversion through stabilization of PRDM16 protein. Cell Metab. 2012;15:395-404

33. Giordano A, Frontini A, Cinti S. Convertible visceral fat as a therapeutic target to curb obesity. Nat Rev Drug Discov. 2016;15:405-24.

\section{Publisher's Note}

Springer Nature remains neutral with regard to jurisdictional claims in published maps and institutional affiliations.
Ready to submit your research? Choose BMC and benefit from:

- fast, convenient online submission

- thorough peer review by experienced researchers in your field

- rapid publication on acceptance

- support for research data, including large and complex data types

- gold Open Access which fosters wider collaboration and increased citations

- maximum visibility for your research: over $100 \mathrm{M}$ website views per year

At $\mathrm{BMC}$, research is always in progress.

Learn more biomedcentral.com/submissions 